\title{
Relaciones económicas España-México en la era de la globalización. Las exportaciones de España
}

\author{
José Luis Alonso Santos (a), María Teresa Sánchez Salazar (b) \\ (a) Departamento de Geografía , Universidad de Salamanca, jlalonso@usal.es, http://orcid.org/0000-0001-6083-6297 \\ (b) Instituto de Geografía, Universidad nacional Autónoma de México, mtss@igg.unam.mx
}

\begin{abstract}
Resumen
Los intercambios comerciales entre México y España trascienden las relaciones económicas y enraízan con las históricas afinidades de identidad y culturales. La globalización no ha quebrado esa sólida relación. La incorporación de México al Mercado de América del Norte y el Tratado de Libre Comercio UE-México desde 2000, han redefinido el marco regulador de los intercambios. El texto analiza los intercambios en los años 90 y su encaje en el marco regulador del TLC y con la Unión Europea. Sigue el análisis en detalle de las exportaciones españolas a México y concluye con unas observaciones de oportunidad para nuevos segmentos de mercado y constata las debilidades que perviven en el comercio de España hacia México. La metodología seguida tiene como soporte el análisis de la base de datos ESTACOM elaborada por ICEX con desglose de la información por sector y rama de actividad (CNAE-2009), país de destino y por comunidad autónoma de origen. El Banco de México presenta datos de las importaciones y exportaciones con España facilitando el contraste de indicadores.
\end{abstract}

Palabras clave: España-México, comercio internacional, exportaciones, intercambios económicos.

\section{Abstract}

Commercial exchanges between Mexico and Spain transcend economic relations and take root with historical identity and cultural affinities. Globalization has not broken that solid relationship. The incorporation of Mexico to the North American Market and the EU-Mexico Free Trade Agreement since 2000 have redefined the regulatory framework for exchanges. The text analyzes the exchanges in the $90 \mathrm{~s}$ and its fit in the regulatory framework of the FTA and with the European Union. It follows the detailed analysis of Spanish exports to Mexico and concludes with some observations of opportunity for new market segments and confirms the weaknesses that persist in the trade of Spain to Mexico. The methodology followed is based on the analysis of the ESTACOM database prepared by ICEX with breakdown of information by sector and branch of activity (CNAE-2009), country of destination and by autonomous community of origin. The Bank of Mexico presents data on imports and exports with Spain, facilitating the contrast of indicators.

Keywords: Spain-Mexico, international trade, exports, economic exchanges.

\section{ANTECEDENTES Y ESTADO DEL TEMA. OBJETIVOS, FUENTES Y METODOLOGÍA}

Aproximarse a la naturaleza de las relaciones económicas de España con México no puede hacerse al margen de las históricas relaciones culturales y el arraigo de la amistad pues han de interpretarse como vehículos de estímulo del desarrollo de las relaciones económicas entre ambos países. Relaciones que se desarrollan en un contexto histórico del comercio internacional que experimenta una fuerte expansión en la segunda mitad del siglo veinte en los países capitalistas desarrollados o no, al amparo de la reglamentación del GATT (General Agreement on Tariffs and Trade) y sus Rondas, lo que exige la implantación en su política económica de prácticas y procesos de producción que generen ventajas competitivas para sus bienes en los mercados internacionales. En ese contexto de internacionalización de las economías nacionales, países como España y México caminan con rezago en la liberalización de sus mercados hasta mediados de los años 80 en el caso de España (integración al Mercado Común Europeo -enero 1986-) y bien entrados los años 90 (1994) en el caso de México (asociación al Tratado de Libre Comercio de América del Norte -TLC- e incorporación a la OCDE) lo que cuadra bien con la observación del profesor J. Velarde, que citando a The Economist, dice que en los años finales de la anterior centuria en Iberoamérica "muchos gobiernos proclamarán su compromiso con el libre comercio, mientras, de manera discreta, les aprietan las clavijas a las importaciones" (Velarde, 1999:52) debido a que mantienen un desarme arancelario limitado a causa de su arraigado nacionalismo económico. 
Una vez España se incorpora al mercado Común Europeo y posteriormente México lo hace al TLC, la relación económica bilateral se ve incluso potenciada por el sentimiento de que ambos sirven de puente para los mercados de los nuevos socios, si bien sostienen los autores del estudio Las relaciones España-México (Informe ELCANO, 2016: 28) ni España ni México necesitan del otro para acceder al mercado del Norte de América en el caso de España o a los mercados de la Unión Europea por parte de México.

Los intercambios comerciales España/México 2000-2017 presentan frecuentes alternancias superávit/déficit si bien el saldo final es de déficit para España tanto con datos de ICEX como del Banco de México. La posición de México como cliente de las mercancías españolas a escala internacional, en el año 2000 su nivel apenas alcanza el 1,2 por ciento mientras el porcentaje más alto corresponde a 2006 con el 1,8 por ciento y en 2017 es el 1,6 por ciento. Entre los principales clientes de los bienes españoles, en 2016 ocupa el puesto 13 y desciendo al 18 entre los suministradores de bienes (Informe ICEX 2017: 5-6).

Dadas las históricas relaciones comerciales, el desarrollo económico alcanzado por ambos países, la gran apertura comercial existente y la conveniente diversificación geográfica del comercio exterior de México tras cuestionar EE.UU. el TLC, cabe esperar estrategias bilaterales una vez renovado el acuerdo comercial México-UE, orientadas a potenciar los intercambios pues existen oportunidades (sectores/nichos de sector) a implementar en ambas direcciones.

Contextualizado el tema, el texto presenta las relaciones comerciales bilaterales en los años 90 del siglo XX e identifica el marco regulador de las relaciones económicas México-España fraguadas en el contexto bilateral primero y en el marco de los acuerdos multilaterales con el TLC primero y con la U E después. El tercer apartado de 2000 al presente, desglosa la naturaleza e intensidad de las exportaciones españolas a través de la base de datos ESTACOM elaborada por ICEX (Instituto Español de Comercio Exterior) e información de la Secretaria General de Comercio Exterior. Fuente que posibilita el seguimiento desagregado por sector y rama de actividad, por país de destino o comunidad autónoma de origen, tanto en valor como en volumen de las exportaciones e importaciones por años entre España y México. El Banco de México también facilita información desagregada para el análisis de las importaciones y exportaciones con España, lo que estimula contrastar los datos estadísticos. Las conclusiones finales conforman el cuarto apartado del texto.

\section{LOS INTERCAMBIOS COMERCIALES EN LOS AÑOS NOVENTA. LIBERALIZACIÓN Y ESTRATEGIAS DE POTENCIACIÓN DEL COMERCIO. EL ACUERDO COMERCIAL CON LA UE.}

En el cuarto final del siglo XX el comercio bilateral estará marcado por la alternancia de años de déficit y superávit según los ciclos económicos de ambas economías. Antes del ingreso en el mercado común europeo, hacia 1980, las exportaciones de España a México apenas cubren el 41,30 por ciento del valor de unas importaciones de 691,4 millones de dólares, en un contexto en el que América Latina (19 países) representa más del 10 por ciento de las ventas al exterior de España y cobertura del 83,9 por ciento del valor de las compras de España en la región (Instituto de Cooperación Iberoamericana 1981:48).

En los años noventa, de 1993 a 1999, España vende a México por valor de 7.373,6 millones de dólares y México a España por 6.086,6 millones. Montos de intercambios que para la economía de México representan el 0,9 de sus ventas al mundo y el 1,1 de sus compras y que, señala Ceceña, sitúan a España como tercer cliente de México detrás de Estados Unidos y Canadá, a la vez que "México es el tercer importador de productos españoles en Latinoamérica y su octavo socio comercial a nivel mundial" (Ceceña 2000:77). Para la economía española, el comercio con México en 2000 representa el 1,2 por ciento de las ventas al mundo y el 1,0 por ciento de las compras, situando a México como décimo socio comercial más importante en exportaciones y el vigésimo en importaciones.

En los años 90, Argentina aún era el primer socio comercial de España en la región y mercados como Venezuela, Chile o Brasil superan a México, país que tras la crisis económica de diciembre 1994, sufre una grave regresión en 1995 (retroceso del PIB del 5,5\%) si bien el quinquenio siguiente presenta tasa media anual de incremento del PIB del 5,1 por ciento (Informe México 2000:145; Botas 2000:112). La traslación de la depresión económica será automática a las importaciones internacionales (Informe México 2000; Banco de México: 15/02/2018) con regresión del 8,7 por ciento de valor en 1995 respecto de 1994 y con mayor virulencia a las bilaterales con España (pérdida del 48,14\% de valor en1995 sobre el año anterior) que impulsadas en 1993-1994 por el éxito de la línea Rey $^{1}$ experimentan una fuerte desaceleración en 1995-1997 (Ceceña 2000; Moreno y Pérez 2005). No obstante,

\footnotetext{
${ }^{1}$ Línea de crédito a la exportación de bienes de equipo por 1.500 millones de dólares gestionada por el ICO .
} 
la crisis del peso, en absoluto empaña el vigor del comercio exterior de México en los años noventa pues presenta una tasa media anual de crecimiento del 15 por ciento "la tasa más alta registrada en el mundo en los años 90" (Blanco 2000:33) con balance de las exportaciones en 1999 del 262,8 por ciento sobre el valor de 1993 y del 217,2 por ciento las importaciones.

Al filo del cambio de siglo la situación comercial bilateral muestra balances muy superiores a los de fechas precedentes. En 2000 el valor conjunto de las compras y ventas entre ambos países fue superior en el 87 por ciento al de 1980 que ascendía a 1.585 millones de dólares (Romero 2001/2002:73). Por su parte, las exportaciones de España escalan al 361,17 por ciento del valor del deprimido bienio 1995-1996 posicionando al país como el socio comercial más importante en América Latina. En suma, México se abre al presente siglo como primer socio comercial de España en la región (Moreno y Pérez 2005: 227), situación ininterrumpida hasta la actualidad, excepción hecha del año 2013 en que las ventas a Brasil suben al 23,7 por ciento de frente al 21,0 que alcanzan las de México sobre las de América Latina-Caribe.

En esos años noventa, las exportaciones de España a México presentan alto componente en bienes de equipo, semimanufacturas, manufacturas y sector del automóvil, con destacada presencia de bienes como automóviles, material eléctrico, maquinarias-herramientas, libros, productos cerámicos, confección, calzado y vinos (Moreno y Pérez 2005:229; Rodrigo y Arce 1999:128).

El marco de las relaciones económicas España-México en esos años se verá tensionado por el proceso de liberalización de la economía de México en sus relaciones económicas específicas con los países del TLC desde enero de 1994 y, desde julio de 2000, el Acuerdo de Asociación Económica, Concertación Política y Cooperación con la Unión Europea. Acuerdos que dan a México "un acceso libre, con seguridad jurídica y mecanismos eficaces de resolución de conflictos, a sus dos principales socios comerciales, cubriendo entre ambos cerca del 95\% del comercio exterior mexicano" (López 2001/2002:115). Para México los espacios del TLC y la UE son mercados muy desiguales para sus intercambios con tendencia incluso al incremento a partir de 1994 (el TLC acapara el 85\% de sus exportaciones a la vez que la UE pierde peso (Riva de la 2000: 63; Botas 2000:113; Informe México 2000:170) por lo que: "la diversificación del riesgo a plazo es una de las principales motivaciones que llevó al gobierno de México a buscar un acuerdo de Libre Comercio con la UE" (Riva de la 2000:63).

Las relaciones económicas bilaterales serán estimuladas por la firma de distintos acuerdos y el desempeño de instrumentos diversos de promoción, destacando entre ellos los que establecen normas claras y dan seguridad a las empresas o abren líneas de crédito que fomentan las exportaciones e inversiones (Oficina Económica 2004:11/12; Moreno y Pérez 2005:234-235). Son el Tratado General de Cooperación y Amistad que desde 1990 abre una potente línea de crédito en apoyo a las exportaciones de bienes y servicios o inversiones desde España hacia México, así como el acuerdo de Promoción y Protección de Recíproca de Inversiones (APRI) de diciembre de 1996. El Instituto de Crédito Oficial (ICO) y el Instituto Español de Comercio Exterior (ICEX) serán los organismos oficiales encargados de su ejecución y seguimiento.

\section{LAS EXPORTACIONES DE ESPAÑA A MÉXICO EN EL SIGLO XXI}

En los años transcurridos del presente siglo el comercio de España con América Latina-Caribe presenta un bajo perfil ya que apenas representa el 5,6 por ciento de las ventas totales al exterior ${ }^{2}$ de $2000 / 2017$ e incluso sufre deterioro en los bienios $2003 / 2004$ y $2008 / 2009$ con niveles inferiores al cinco por ciento. Pese a ello, hay que señalar que no se observan mayores esfuerzos para incrementar la participación de los países de América Latina en el comercio exterior hasta bien avanzada la crisis económica cuando la débil demanda interna obliga a las empresas a abrir mercados en el exterior de modo que de 2012 a 2015 las exportaciones hacia América Latina se expanden y retornan a niveles superiores al seis por ciento (6,47\% en 2013) de las exportaciones totales como sucedía en 2000 . El mercado de A.Latina-Caribe actual representa más del siete por ciento del PIB mundial, sus clases medias se han incrementado y países como Brasil y México se sitúan entre las 15 mayores economías del mundo en PPA, como destacan los autores del Informe ELCANO (¿Por qué importa América Latina?, 2017: 37). Como hemos documentado (Alonso, 2018: 18) en los peores años del quinquenio inicial del siglo el deterioro de las ventas a México fue menor que el registrado en el conjunto de América Latina-Caribe y sus grandes mercados de Argentina y Brasil. En realidad, los intercambios España/ México se han incrementado en volumen y en porcentaje tanto sobre el comercio regional como sobre el total mundial.

${ }^{2}$ La Ley 14/2013 de apoyo a los emprendedores y la internacionalización dará lugar al primer Plan Estratégico de Internacionalización $2014-2015$ antecedente de La Estrategia de Internacionalización de la Economía Española 2017-2027. 


\subsection{Grado de las exportaciones $2000-2017$ y sus fases}

Las ventas totales de la economía española al exterior de 2000 a 2017 experimentan un crecimiento notable pues más que doblan su valor (223,2\%) al igual que hacia América Latina-Caribe $(207,3 \%)$ si bien las realizadas a México presentan evolución más vigorosa ya que en 2017 suponen el 304,6 por ciento del valor en 2000. La figura 1 muestra las ventas a México respecto a A. Latina-Caribe y al comercio exterior total.

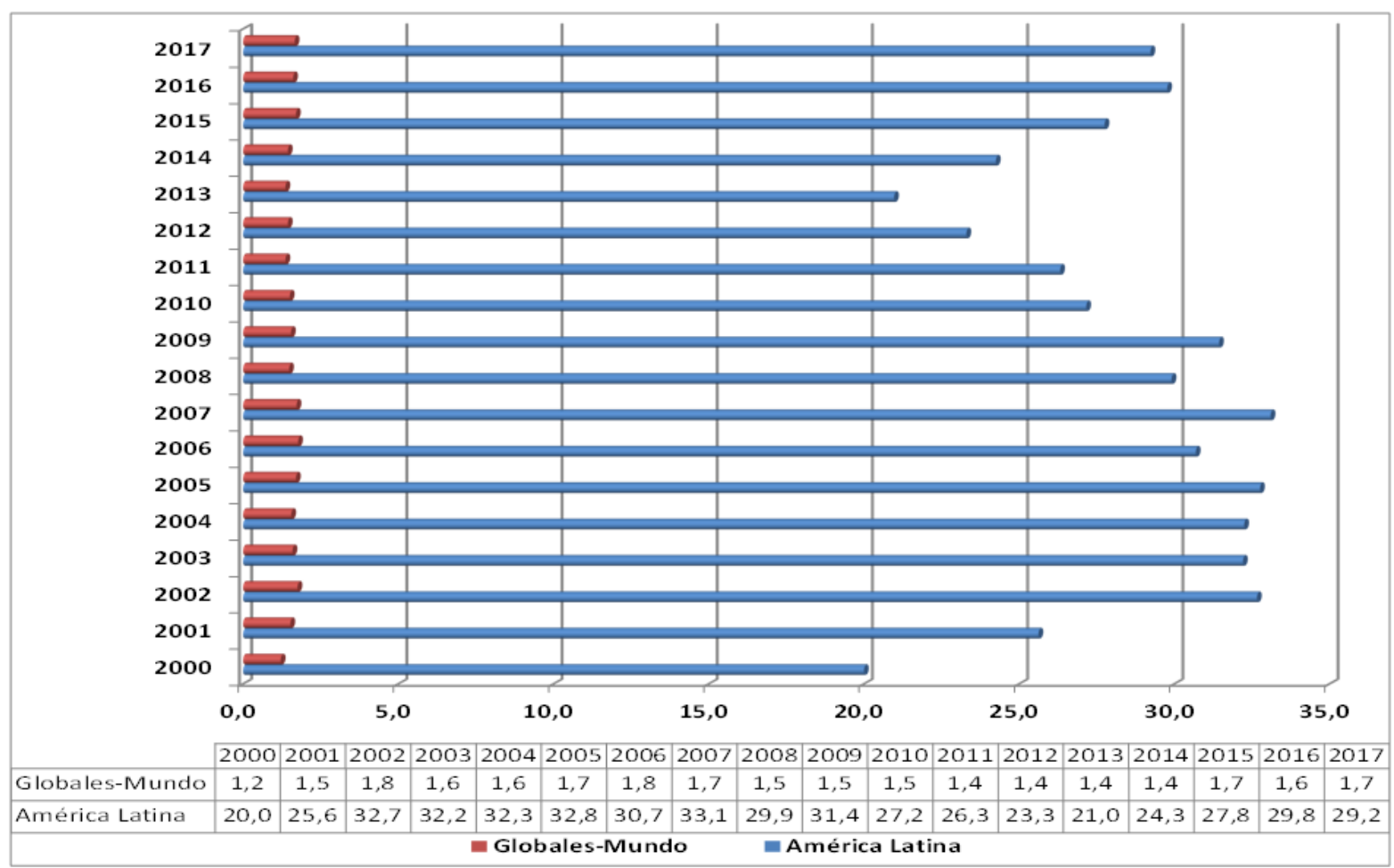

Figura 1 - Exportaciones (\%) de España a México respecto a América Latina y al Mundo 2000-2017. Fte. ICEX. Estacom.

Mientras que en las décadas finales del siglo XX hasta mediados de los años 90, Argentina fuera el mercado principal en el comercio de España con A. Latina, desde los últimos años de la década al presente, México junto a Brasil, engrosan la lista de países de interés estratégico para la economía española pues constituyen dos potentes mercados que sumados superan ampliamente el 50 por ciento de la IED de España en la región (Sánchez, Alonso y Casado, 2017: 12) y apenas les restan unos puntos en el monto de las exportaciones (45,8\% media 2016-2017). Si la IED de España en Brasil supera ampliamente a la recibida por México: 59.327,6 millones de euros por 35.116,8 millones de euros de 1993 a 2015 (Cepal 2000; Alonso, Mendes y Guarnieri, 2017:181) en comercio, excepción hecha de 2013, México supera en mucho a Brasil pues de 2000 a 2017 acapara el 27,6 por ciento de las exportaciones a la región mientras Brasil representa el 17,7 por ciento.

El notable incremento del comercio bilateral arroja saldo global negativo para España pues las ventas de 53.112,6 millones/€ apenas cubren el 95,5 por ciento de las compras por 55.592,3 mills/€. Saldo no exento de años de alternancia déficit/superávit como muestra la figura 2. Hay años como 2000, 2005 y 2008 con saldo negativo para España pero el deterioro grave y prolongado de las ventas españolas define al quinquenio 2010-2014 con muy grave de déficit de cobertura en 2012 (apenas 57,1\%) y 2013 (58,8\%). El periodo más amplio de saldo positivo para las exportaciones de España es el cuatrienio 2001-2004 así como los tres últimos años registran amplios saldos positivos.

Que el déficit comercial caracterice al periodo 2000-2017, no pone en cuestión que en 2007 el valor de las exportaciones respecto a 2000 sea el 210,8 por ciento y en 2017 se haya incrementado al 304,6 por ciento (144,5\% sobre el valor de 2007). Son únicamente cinco los años en los que se registran pérdidas de valor de las exportaciones respecto del precedente $(2003,2008,2009,2013$ y 2016). De ellos, el bienio 2008-2009 presenta tasas interanuales negativas severas $(-11,8 \%$ en 2008 y $-12,0 \%$ en 2009$)$. Es de cierta importancia $(-6,1 \%)$ la 


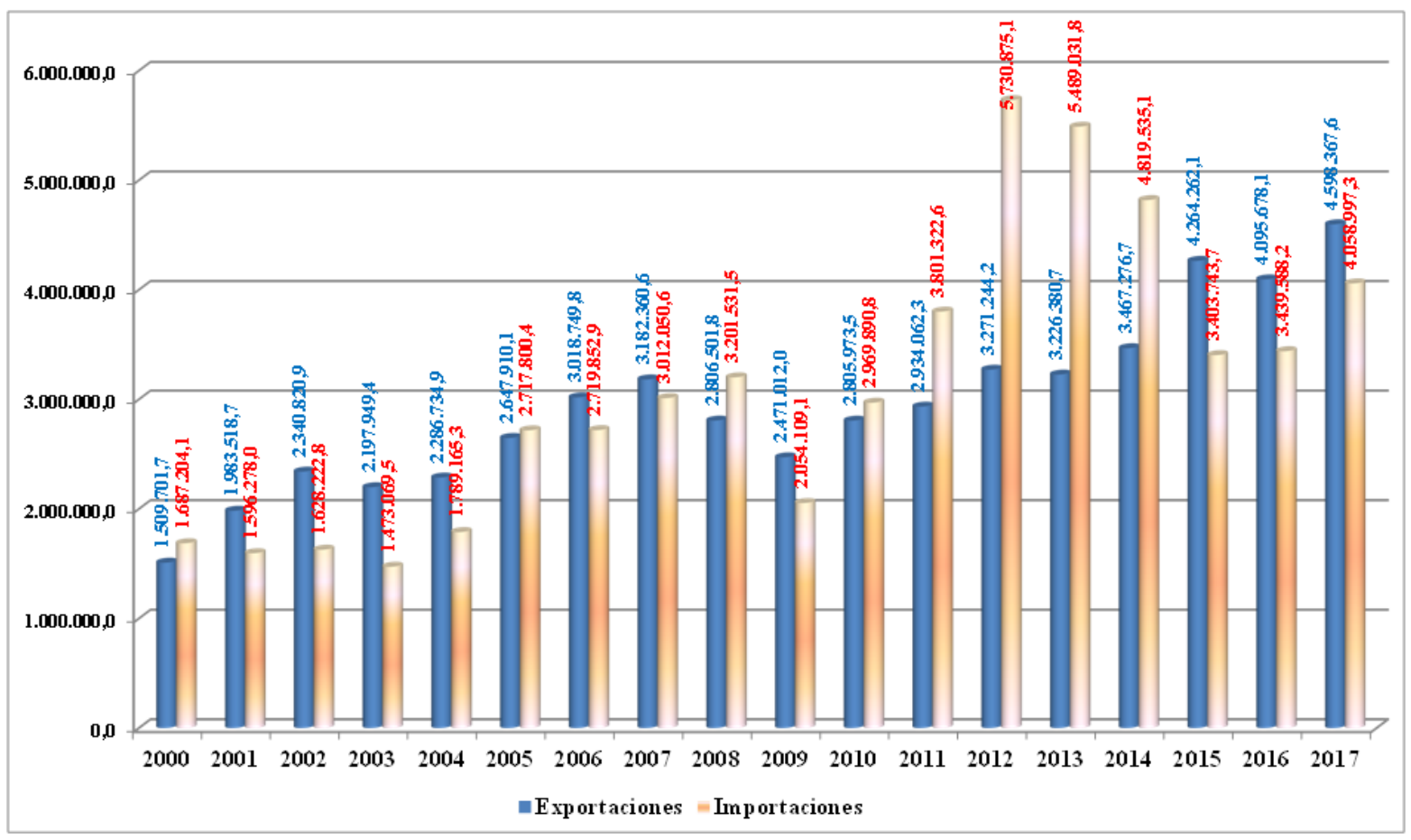

Figura 2 - Comercio entre España y México 2000-2017. Miles de euros. Fte. ICEX. Estacom.

pérdida de valor en 2003, fecha en que registran saldo negativo importante respecto el año anterior capítulos como edición además de actividades manufactureras tan variadas como alimentación, cuero y calzado, química, productos metálicos, fabricación de equipo eléctrico o vehículos de motor. Las exportaciones de 2008-2009 sufren contracción muy marcada y en 2008 su valor se redujo al 89,8 por ciento respecto a 2007 para bajar al 77,6 por ciento en 2009, año en que proliferan ramas de actividad cuyos bienes sufren un descalabro en relación a los niveles de 2007. Registran pérdidas superiores al 50 por ciento las ramas de fabricación de muebles: 35,1\%, así como recogida y tratamiento de residuos sólidos: $46,2 \%$. Nueve ramas presentan valores inferiores a la media (77,6\%) del conjunto (otras industrias manufactureras; edición; vehículos a motor; maquinaria y equipo n.c.o.p.; productos informáticos, electrónicos-ópticos; productos metálicos; otros productos minerales; productos de caucho-plásticos; industria textil). Registran pérdida de valor inferior a la media otras ocho ramas (alimentación, bebidas, confección, cuero y calzado, papel, coquerías y refino de petróleo, química y productos farmacéuticos). En este contexto de regresión comercial, la excepción viene por el incremento de valor de metalúrgia-fab. hierro... $(106,1 \%)$, fabricación de otro material de transporte $(107,9 \%)$ y fabricación de material y equipo eléctrico (123,5\%).

Frente a las coyunturas de regresión de las exportaciones, hasta ocho años presentan sobre el precedente tasas de incremento por encima del 10 por ciento. La grave depresión del bienio 2008-2009 se produce después de una etapa de ocho años de sostenido y sólido ritmo de incremento de las exportaciones excepción hecha de 2003. En esos años la tasa interanual media de incremento del 11,8 por ciento fue más robusta que la del 8,1 por ciento de la etapa que se abre en 2010 hasta 2017, en la que se registra 2013 y 2016 con suaves tasas de regresión $(-1,4$ y $-3,9 \%$ respectivamente).

Las exportaciones a México se presentan muy concentradas en el sector de la industria manufacturera (93,5\%), muy reducida presencia del sector editorial y comunicación $(3,3 \%)$ y el sector tratamiento de aguas y residuos sólidos $(1,6 \%)$ e insignificante presencia de las industrias extractivas $(0,8 \%)$, actividades no clasificadas $(0,6 \%)$ sector primario $(0,2 \%)$, etc.. La situación no siempre fue esta como indican los datos del cuadro-1. En los años anteriores a la crisis económica la polarización en torno a la industria manufacturera no era tan potente como en los años recientes pues su valor del 89,9 por ciento era varios puntos inferior al de los años 2008-2017.

Un análisis más detallado de la información de Estacom en base a la clasificación de actividades de CNAE2009, permite seguir el comportamiento de cada rama de actividad. El cuadro-2 muestra el peso de las 10 ramas de mayor valor aportado de 2000 a 2017 contrastado con los bienios inicial, intermedio y final. El resultado es 
Cuadro 1 - Exportaciones de España a México. Fases en el tiempo. Miles de euros. Fte. ICEX. Estacom.

\begin{tabular}{|c|c|c|c|c|c|c|}
\hline \multirow[b]{2}{*}{ Ram as CNAE-2009 } & \multicolumn{2}{|c|}{$2000-2007$} & \multicolumn{2}{|c|}{ 2008-2017 } & \multicolumn{2}{|c|}{$2000-2017$} \\
\hline & Miles/€ & $\%$ & Miles/€ & $\%$ & Miles/€ & $\%$ \\
\hline Agricultura, ganaderia, caza y servicios relacionados con las mismas & $24.052,7$ & 0,1 & $75.610,6$ & 0,2 & $99.663,3$ & 0,2 \\
\hline Silvicultura y explotación forestal & 277,2 & 0,0 & 719,5 & 0,0 & 996,6 & 0,0 \\
\hline Pesca y acuicultura & 133,1 & 0,0 & 776,1 & 0,0 & 909,3 & 0,0 \\
\hline Sector Primario & $24.463,0$ & 0,1 & $77.106,2$ & 0,2 & $101.569,2$ & 0,2 \\
\hline Extracción de antracita, hulla y lig nito & 12,9 & 0,0 & 0,2 & 0,0 & 13,1 & 0,0 \\
\hline Extracción de crudo de petróleo y gas natural & & 0,0 & $155.895,0$ & 0,5 & $155.895,0$ & 0,3 \\
\hline Extracción de minerales metálicos & $5.872,4$ & 0,0 & $74.918,4$ & 0,2 & $80.790,8$ & 0,2 \\
\hline Otras industrias extractivas & $67.727,8$ & 0,4 & $92.417,4$ & 0,3 & $160.145,1$ & 0,3 \\
\hline Indus trias Extractivas & $73.613,0$ & 0,4 & $323.230,8$ & 1,0 & $396.843,8$ & 0,7 \\
\hline Industria de la alimentación & $635.063,0$ & 3,3 & $1.412 .460,8$ & 4,2 & $2.047 .523,8$ & 3,9 \\
\hline Fabricación de bebidas & $475.811,2$ & 2,5 & $981.234,4$ & 2,9 & $1.457 .045,6$ & 2,7 \\
\hline Indus tria del tabaco & $3.219,1$ & 0,0 & $2.088,4$ & 0,0 & $5.307,4$ & 0,0 \\
\hline Industria textil & $567.858,0$ & 3,0 & $550.261,5$ & 1,6 & $1.118 .119,5$ & 2,1 \\
\hline Confección de prendas de vestir & $1.138 .835,9$ & 5,9 & $2.607 .215,6$ & 7,7 & $3.746 .051,6$ & 7,1 \\
\hline Industria del cuero y del calzado & $333.945,9$ & 1,7 & $546.435,7$ & 1,6 & $880.381,6$ & 1,7 \\
\hline Industria de la madera y del corcho, excepto muebles; cesteria y espa & $61.247,4$ & 0,3 & $144.502,1$ & 0,4 & $205.749,4$ & 0,4 \\
\hline Industria del papel & $281.135,7$ & 1,5 & $477.138,7$ & 1,4 & $758.274,3$ & 1,4 \\
\hline Artes gráficas y reproducción de soportes grabados & $1.658,0$ & 0,0 & $1.184,9$ & 0,0 & $2.842,9$ & 0,0 \\
\hline Coquerias y refino de petróleo & $1.291 .889,7$ & 6,7 & $1.464 .440,6$ & 4,3 & $2.756 .330,3$ & 5,2 \\
\hline Industria quimica & $1.351 .902,2$ & 7,1 & $2.780 .942,3$ & 8,2 & $4.132 .844,5$ & 7,8 \\
\hline Fabricación de productos farmacéuticos & $366.523,3$ & 1,9 & $959.022,9$ & 2,8 & $1.325 .546,2$ & 2,5 \\
\hline Fabricación de productos de caucho y plásticos & $430.553,4$ & 2,2 & $804.608,5$ & 2,4 & $1.235 .161,9$ & 2,3 \\
\hline Fabricación de otros productos minerales no metálicos & $632.085,6$ & 3,3 & $771.114,3$ & 2,3 & $1.403 .199,9$ & 2,6 \\
\hline Metalurg ia; fabricación de productos de hierro, acero y ferroaleacion & $526.246,8$ & 2,7 & $1.194 .056,9$ & 3,5 & $1.720 .303,7$ & 3,2 \\
\hline Fabricación de productos metálicos, excepto maquinaria y equipo & $1.009 .071,8$ & 5,3 & $1.742 .129,8$ & 5,1 & $2.751 .201,5$ & 5,2 \\
\hline Fabricación de productos infomáticos, electrónicos y ópticos & $682.052,4$ & 3,6 & $696.722,5$ & 2,1 & $1.378 .774,9$ & 2,6 \\
\hline Fabricación de material y equipo eléctrico & $767.344,4$ & 4,0 & $2.824 .007,5$ & 8,3 & $3.591 .351,9$ & 6,8 \\
\hline Fabricacion de maquinaria y equipo n.c.o.p. & $2.663 .840,1$ & 13,9 & $4.254 .608,1$ & 12,5 & $6.918 .448,1$ & 13,0 \\
\hline Fabricacion de vehiculos de motor, remolques y semirremolques & $2.795 .496,8$ & 14,6 & $5.313 .664,7$ & 15,7 & $8.109 .161,6$ & 15,3 \\
\hline Fabricación de otro material de transporte & $615.614,0$ & 3,2 & $2.008 .242,1$ & 5,9 & $2.623 .856,2$ & 4,9 \\
\hline Fabricación de muebles & $222.115,1$ & 1,2 & $327.312,8$ & 1,0 & $549.428,0$ & 1,0 \\
\hline Otras industrias manufactureras & $381.646,0$ & 2,0 & $586.717,9$ & 1,7 & $968.363,9$ & 1,8 \\
\hline Industria Manufacturera & $17.235 .155,7$ & 89,9 & $32.450 .113,0$ & 95,6 & $49.685 .268,8$ & 93,6 \\
\hline Suminis tro de energía eléctrica, gas, vapor y aire acondicionado & 1,0 & 0,0 & & 0,0 & 1,0 & 0,0 \\
\hline Recogida y tratamiento de aguas residuales & & 0,0 & & 0,0 & & 0,0 \\
\hline Recogida, tratamiento y eliminación de residuos; valorización & $665.383,8$ & 3,5 & $163.941,6$ & 0,5 & $829.325,4$ & 1,6 \\
\hline Suminis troy tratamiento agua, resíduos sólidos y descont. & $665.383,8$ & 3,5 & $163.941,6$ & 0,5 & $829.325,4$ & 1,6 \\
\hline Edición & $1.004 .368,7$ & 5,2 & $697.877,3$ & 2,1 & $1.702 .246,0$ & 3,2 \\
\hline Actividades cinematográficas, de video y de programas de televisión & $23.201,6$ & 0,1 & $5.626,5$ & 0,0 & $28.828,0$ & 0,1 \\
\hline Información, comunic aciones & $1.027 .570,3$ & 5,4 & $703.503,8$ & 2,1 & $1.731 .074,1$ & 3,3 \\
\hline Servicios técnicos de arquitectura e ing enieria; ensayos y analisis téc & 223,7 & 0,0 & 31,7 & 0,0 & 255,4 & 0,0 \\
\hline Otras actividades profesionales, cientificas y técnicas & 340,1 & 0,0 & 31,2 & 0,0 & 371,2 & 0,0 \\
\hline Actividades profesionales, cientific 0 -técnic as & 563,8 & 0,0 & 62,8 & 0,0 & 626,7 & 0,0 \\
\hline Actividades de creación, artisticas y espectáculos & $5.721,2$ & 0,0 & $17.179,8$ & 0,1 & $22.901,1$ & 0,0 \\
\hline Actividades de bibliotecas, archivos, museos y otras actividades cul & 505,0 & 0,0 & $1.899,9$ & 0,0 & $2.404,9$ & 0,0 \\
\hline Actividades artístic as y recreativas & $6.226,3$ & 0,0 & $19.079,7$ & 0,1 & $25.306,0$ & 0,0 \\
\hline Otros servicios personales & & 0,0 & 24,1 & 0,0 & 24,1 & 0,0 \\
\hline Actividades no clas ific adas & $134.769,1$ & 0,7 & $203.696,7$ & 0,6 & $338.465,8$ & 0,6 \\
\hline Total Exportaciones & $19.161 .297,6$ & 100,0 & $33.940 .759,0$ & 100,0 & $53.108 .505,0$ & 100,0 \\
\hline
\end{tabular}

que el 72,3 por ciento de lo exportado en el periodo corresponde a las 10 ramas que encabezan el ranking si bien se registran diferencias en el tiempo tanto en porcentaje como en ramas principales. Entre las 10 mayores ramas, seis presentan monto de ventas importante en todo el tiempo, la industria alimentaria está ausente en el bienio inicial; deben su presencia entre las 10 mayores a la envergadura de sus ventas en momentos puntuales coquerías y refino de petróleo en 2007/2008 y en 2016/2017 emergen las ramas de fabricación de otro material de transporte, metalúrgia-fabricación de hierro y fabricación de productos farmacéuticos. En suma, de forma regular unas, más puntualmente otras, son 15 las ramas que aportan más de las 3/4 partes de las exportaciones.

Empresas y territorio son actores imprescindibles del proceso exportador. Respecto a quién exporta, el Informe $^{3}$ facilitado por ICEX sobre las empresas exportadoras a México en 2017 facilita información sobre las em-

${ }^{3}$ Informe solicitado a ICEX el 19/03/2018 y elaborado a partir de los datos suministrados por el Departamento de Aduanas e Impuestos Especiales de la AEAT. 
Cuadro 2 - Valor en \% de las diez ramas mayores sobre las exportaciones totales. Fte. Datos Estacom.

\begin{tabular}{|c|c|c|c|c|}
\hline Ramas de actividad & 2000-2017 & $2000 / 2001$ & $2007-2008$ & 2016-2017 \\
\hline Fabricación de vehiculos de motor, remolques y semirremolques & 15,3 & 14,8 & 13,3 & 16,5 \\
\hline Fabricación de maquinaria y equịo n.c.o.p. & 13,0 & 16,0 & 12,2 & 13,9 \\
\hline Confección de prendas de vestir & 7,1 & 4,8 & 7,0 & 8,4 \\
\hline Fabricación de materialy equipo eléctrico & 6,8 & 4,3 & 5,1 & 8,2 \\
\hline Coquerías y refino de petróleo & 5,2 & & 14,3 & \\
\hline Fabricación de otro material de transporte & 4,9 & & & 6,4 \\
\hline Industria de la alimentación & 3,9 & & 2,9 & 5,2 \\
\hline Metalurgia; fabricacion de productos de hierro, acero y ferroaleaciones & 3,2 & & & 3,2 \\
\hline Edición & & 8,0 & 3,2 & \\
\hline Recogida, tratamiento y eliminación de residuos; valorización & & 4,3 & 3,2 & \\
\hline Valor de las 10 ramas sobre total & 72,3 & 73,4 & 72,1 & 78,7 \\
\hline
\end{tabular}

presas exportadoras entre 2012 y 2017 y las clasifica por valor de lo exportado desde 2013. Los datos confirman la tendencia general del país en cuento al incremento de exportadores a México en los años recientes habiendo crecido el 23,2 por ciento (de 11.154 en 2012 a 13.739 en 2017) indicador que representa el 8,5 por ciento de los exportadores de España aunque apenas aportan el 1,7 por ciento del valor exportado por el país en 2017.

El Informe revela que buen número de empresas (73,7\% en 2013 y 72,3\% en 2017) incorporadas al mercado de México registran volumen de ventas muy reducido (hasta $50.000 €$ ) aunque en claro incremento (ascenso del 1,1 a $1,5 \%$ del total), mientras las empresas que exportan por encima de cinco millones/€ son muy pocas pero su aportación extraordinaria con tendencia al incremento (50,3\% en 2013 y 56,0\% en 2017). El Informe también muestra la concentración en los niveles inferiores de las ventas de los exportadores irregulares mientras los regulares se concentran en los altos.

\section{2. La naturaleza de los bienes exportados y sus cambios según composición}

El perfil de las exportaciones a México muy concentrado en la industria manufacturera se ha ido reforzando con los años hasta representan el 97,5 por ciento del total en el bienio 2016-2017 frente al 86,4 por ciento en el bienio 2000-2001 o el 92,1 por ciento de 2007-2008. Presentadas por el sector de actividad en el que se encuadran sus productos, las exportaciones a México arrojan los valores que se recogen en el cuadro 3 y la figura 3.

El sector bienes de equipo aunque pierde peso en el total respecto a los años 90 de la centuria anterior (Moreno y Pérez 2005:228) sigue ocupando un lugar destacado con valor superior al 31,3 por ciento de las exportaciones del periodo si bien registra marcados contrastes en el tiempo como indican los datos de 2007-2008. Rasgo a considerar es que su peso en el comercio con México es muy superior al que alcanza sobre las exportaciones totales de España. Las manufacturas de consumo, con el 17,6 por ciento son el segundo sector en importancia si bien registran pérdida notable de valor en los años recientes. A pesar de ello, su presencia en el mercado de México es muy superior a la que tiene en las exportaciones totales. Contraria es la imagen del sector del automóvil, con trayectoria bastante regular y tercero en valor $(14,8 \%)$ aunque con protagonismo varios puntos inferior al que adquiere en las exportaciones totales de España. Productos químicos es el cuarto sector en importancia $(11,6 \%)$ y en el tiempo muestra trayectoria bastante regular así como su peso sigue un patrón muy similar al que ofrece en las exportaciones totales del país.

Con menor valor de sus bienes pero también con sólida y regular presencia están los sectores de alimentos, semimanufacturas sin productos químicos e incluso el débil sector de bienes de consumo duradero. Aleatoria es la trayectoria del sector de productos energéticos ${ }^{4}$ y el de materias primas. Sin relevancia en las exportaciones a México (Cámara Española de Comercio 2017:15) ambos tienen limitada presencia las exportaciones de España.

${ }^{4}$ Concentra el 84,2 por ciento de sus ventas de 2006 a 2010 . 


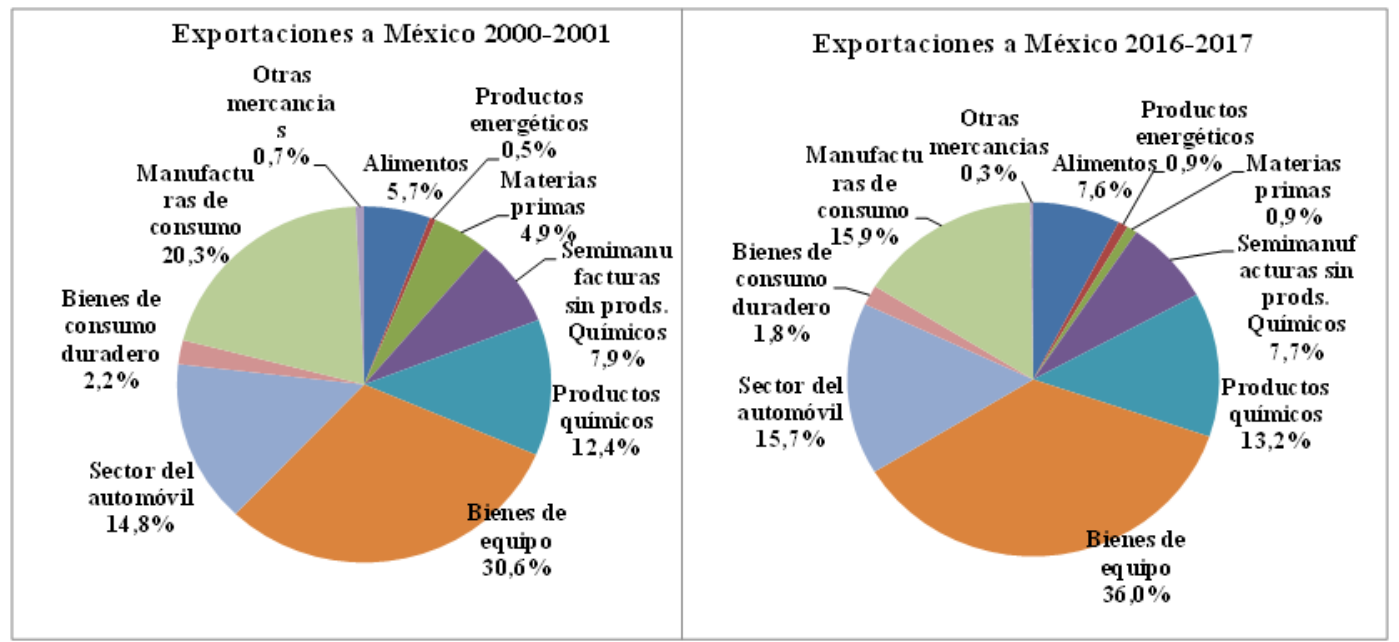

Figura 3 - Exportaciones a México por sectores económicos. Fte. Estacom.

Cuadro 3 - Exportaciones de España a México por sectores económicos. Miles de euros. Fte. Estacom.

\begin{tabular}{|c|c|c|c|c|c|c|c|c|}
\hline Sectores Económicos ICEX & $2000-2001$ & $\% 2000-2001$ & $2007-2008$ & $\%$ 2007-2008 & 2016-2017 & $\%$ 2016-2017 & $2000-2017$ & $\% 2000-2017$ \\
\hline Alimentos & $200.009,8$ & 5,7 & $336.309,4$ & 5,6 & $660.572,9$ & 7,6 & $3.425 .006,8$ & 6,4 \\
\hline Productos energéticos & $18.018,3$ & 0,5 & $864.555,5$ & 14,4 & $75.596,4$ & 0,9 & $2.920 .319,7$ & 5,5 \\
\hline Materias primas & $172.410,9$ & 4,9 & $241.897,6$ & 4,0 & $78.087,8$ & 0,9 & 1.319. 274,5 & 2,5 \\
\hline Semimanufacturas sin prods. Químicos & $276.586,2$ & 7,9 & $416.492,3$ & 7,0 & $669.199,1$ & 7,7 & $4.129 .693,4$ & 7,8 \\
\hline Productos químicos & $432.222,6$ & 12,4 & $561.855,9$ & 9,4 & $1.145 .303,2$ & 13,2 & $6.179 .035,6$ & 11,6 \\
\hline Bienes de equipo & 1.068.717, 1 & 30,6 & $1.532 .211,5$ & 25,6 & $3.132 .210,5$ & 36,0 & $16.628 .349,7$ & 31,3 \\
\hline Sector del automóvil & $515.838,7$ & 14,8 & $727.473,3$ & 12,1 & $1.366 .937,5$ & 15,7 & $7.886 .819,3$ & 14,9 \\
\hline Bienes de consumo duradero & $76.249,6$ & 2,2 & $107.621,6$ & 1,8 & $158.699,6$ & 1,8 & $908.574,8$ & 1,7 \\
\hline Manufacturas de consumo & $707.745,6$ & 20,3 & $1.141 .267,0$ & 19,1 & $1.384 .302,8$ & 15,9 & $9.370 .894,5$ & 17,6 \\
\hline Otras mercancias & $25.421,6$ & 0,7 & $59.178,3$ & 1,0 & $23.136,0$ & 0,3 & $340.251,4$ & 0,6 \\
\hline TOTAL & $3.493 .220,4$ & 100,0 & $5.988 .862,4$ & 100,0 & $8.694 .045,7$ & 100,0 & $53.108 .219,7$ & 100,0 \\
\hline
\end{tabular}

Los energéticos en 2016 respecto a 2015, experimentan fuertes contrastes entre sus componentes pues decaen el 56,5 por ciento las ventas de gas natural mientras los derivados del petróleo se incrementan el 14,9 por ciento (ICE 2017: 51).

Dominan las exportaciones automóviles y motos $(61,6 \%)$ junto a componentes, piezas y accesorios $(38,1 \%)$ en el sector del motor; en el área química destacan productos químicos básicos y jabones, detergentes y artículos de limpieza; en bienes de equipo sobresale la maquinaria industrial en general, motores, generadores y transformadores eléctricos. Otros bienes sólidamente implantados son las prendas de vestir, alimentos (aceites y grasas vegetales, frutas y verduras más lácteos, aportan el 52,3\%), los vinos aportan el 46,3 por ciento del valor de todas las bebidas exportadas al país y su cuantía adquiere gran relevancia cuando se mide en el importante mercado de América Latina. Es éste un mercado para los vinos españoles débil aún pero un clara expansión y donde México ostenta posición muy destacada pues aporta el 54,8 por ciento. El Observatorio Español del Mercado del Vino (OEMV) resalta que las exportaciones a México en 2017 crecieron más del seis por ciento de modo que se refuerza su primacía en valor pero también en volumen al desplazar a los vinos chilenos (Memoria 2017: 23 y Boletín 475). En consonancia con la arraigada presencia de las grandes editoriales españolas en México, los libros importados tienen sólida y regular trayectoria si bien desde 2008 decae su intensidad.

Por último, la naturaleza de los bienes vendidos por España a México puede ser considerada en función del grado de intensidad tecnológica que presentan. En este sentido, la base Estacom presenta el balance que recoge el cuadro-4, que también incorpora los índices para las exportaciones totales de España en las mismas fechas lo que facilita la ponderación de las ventas al mundo y a México.

Las exportaciones a México presentan decreciente peso de las más avanzadas a la vez que durante los años de crisis económica se fortalecen notablemente las de intensidad media-alta de modo que el peso conjunto del 51,7 por ciento en 2001 salta al 57,1 en 2017 en detrimento de los bienes de intensidad media y baja. Comportamiento más positivo que el las exportaciones españolas que si en la actualidad tienen un componente de intensidad alta varios puntos superior a las de México en cambio presentan valores en regresión en intensidad media- 
Cuadro 4 - España. Grado de intensidad tecnológica de las exportaciones. Fte. Estacom 19 marzo 2018.

\begin{tabular}{|c|c|c|c|c|c|c|}
\hline \multirow[t]{2}{*}{ Exportaciones de España } & \multicolumn{2}{|c|}{2001} & \multicolumn{2}{|c|}{2008} & \multicolumn{2}{|c|}{2017} \\
\hline & Miles/€ & $\%$ & Miles/€ & $\%$ & Miles/€ & $\%$ \\
\hline Intensidad Alta & $10.979 .197,1$ & 8,8 & $16.569 .016,9$ & 8,8 & $24.866 .168,8$ & 9,0 \\
\hline Intensidad Media-Baja & $23.218 .673,4$ & 18,7 & $42.327 .497,7$ & 22,4 & $52.363 .442,7$ & 18,9 \\
\hline Intensidad Baja & $24.393 .327,6$ & 19,6 & $35.865 .168,3$ & 19,0 & $61.341 .965,4$ & 22,1 \\
\hline \multirow[t]{2}{*}{ Exportaciones a México } & \multicolumn{2}{|c|}{2001} & \multicolumn{2}{|c|}{2008} & \multicolumn{2}{|c|}{2017} \\
\hline & Miles/€ & $\%$ & Miles/€ & $\%$ & Miles/€ & $\%$ \\
\hline Intensidad Alta & $105.635,3$ & 7,0 & $155.043,8$ & 5,5 & $264.429,5$ & 5,8 \\
\hline No clasificable & $183.865,8$ & 12,2 & $197.846,9$ & 7,0 & $110.297,4$ & 2,4 \\
\hline Total & $1.509 .701,7^{\top}$ & 100,0 & $2.806 .501,8$ & 100,0 & $4.598 .367,6$ & 100,0 \\
\hline
\end{tabular}

alta hasta el punto de que la suma de ambos valores se queda en el 48,2 por ciento mientras en México superan el 57,0 por ciento. Todo indica que la economía de España tiene un problema serio de investigación e innovación técnica que se refleja en el valor añadido de sus exportaciones, circunstancia que implícitamente reconoce el documento "Estrategia de Internacionalización de la Economía Española 2017-2027" cuando sugiere priorizar la producción de bienes de intensidad tecnológica alta ya que "la tasa de exportaciones de alta tecnología está entre las más bajas de la UE" (p. 19).

\section{3. El origen de las exportaciones por CC.AA}

El estudio y conocimiento del origen de los bienes exportados en general o a México en particular, es dimensión relevante del comercio exterior de la economía de España. En especial, desde el inicio de la grave crisis

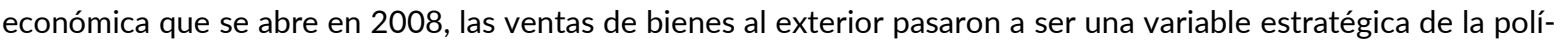
tica económica que ha fraguado notables resultados tanto por su aportación a la actividad económica general en años de muy débil vigor de la demanda interna como porque animó u obligó a dar el salto a la internacionalización de sus mercados a muchas empresas ante la necesidad de sobrevivir.

Un primer hecho contrastado de las exportaciones a México es el valor medio anual de las exportaciones que ha sido desde 2008 el 141,6 por ciento superior al de los años 2000-2007. Únicamente las comunidades de Baleares y Canarias, ambas con reducida exportación, presentan regresión en su exportación anual media (Baleares pierde incluso en valor absoluto). Incrementan su exportación anual media por debajo del total, las comunidades de Andalucía (119,9\%), Cantabria $(128,6)$, Cataluña $(132,4)$, Madrid $(124,6)$ y País Vasco $(125,7)$. Las diez CC.AA. restantes y Ceuta-Melilla, incrementan el valor medio anual por encima de la media total con índices espectaculares en Asturias (355,5\%) y Navarra (410,8\%).

La participación de las CC.AA. en las ventas a México muestra (figura 4) el protagonismo extraordinario de Cataluña a pesar de la regresión en los años de crisis económica. Su aportación es muy superior a su peso real en la economía de España-2016 (19,1\% del PIB) debido a que su industria manufacturera es la mayor de España y está diversificada. Balance similar ofrecen las comunidades de Asturias, C. Valenciana, Galicia, Navarra y País Vasco, todas con mayor índice de exportaciones a México que su PIB nacional. Cantabria y La Rioja registran índice exportador similar a su PIB nacional y las nueve CC.AA. restantes aportan valores siempre inferiores a su PIB nacional. Madrid con PIB rozando el 19 por ciento del nacional apenas aporta el 9,2 de las exportaciones en el periodo así como registra un claro retroceso en los años de crisis. La marcada terciarización de su economía explica su débil capacidad de exportación. En los años de crisis económica respecto a los años previos, pierden porcentaje en las exportaciones además de Baleares y Canarias, las CC.AA. de Andalucía, Cantabria, Cataluña, Madrid y País Vasco. Resulta llamativo que cuatro comunidades (Andalucía, Cataluña, Madrid y País Vasco) que concentran 


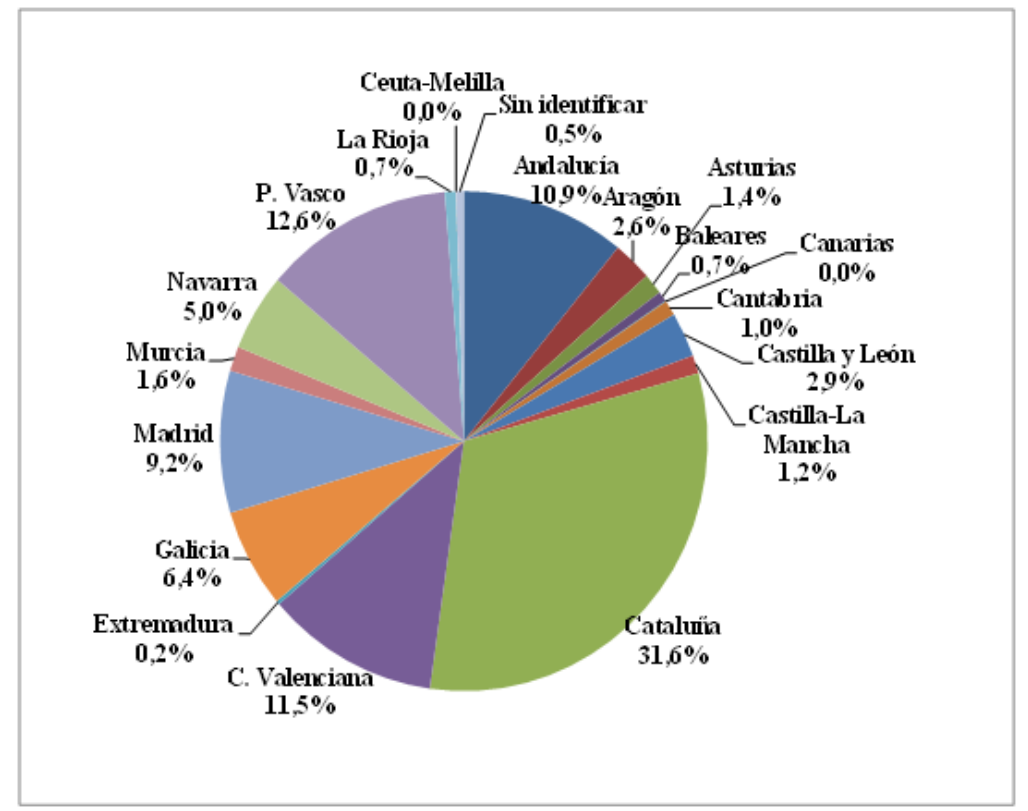

Figura 4 - Exportaciones (\%) de las comunidades autónomas 2000-2017. Fte. Estacom.

más del sesenta y cuatro por ciento de las exportaciones exporten durante la crisis a menor ritmo que el conjunto así como son economías regionales de base económica muy diferente ya que mientras Cataluña y el País vasco son los principales polos industriales del país, Madrid presenta reducida base industrial y Andalucía, aunque ha incrementado su base industrial, sigue muy vinculada al turismo de sol y playa. Con muy dispares grados de mejora en su participación están Aragón, Asturias, Castilla y León, Castilla-La Mancha, C. valenciana, Extremadura, Galicia, Murcia, Navarra y La Rioja.

\section{POTENCIALIDADES ABIERTAS, ESTRATEGIAS A IMPLEMENTAR}

El Plan Integral de Desarrollo de Mercado para el despliegue de estrategias de promoción de las relaciones económicas internacionales como incentivos a pymes, al exportador regular, a sectores como el alimentario, energías renovables, infraestructuras, industria, tics, turismo, culturales (libro), asesoramiento en destino (ICEX. Plan Integral 2015), presenta a México en el grupo de países a los que se presta atención preferente.

La proximidad y afinidad cultural es un vector que debe potenciarse más como vía para que la cultura, el idioma, los intercambios turísticos en ambas direcciones se fortalezcan. Los estudios universitarios y sus intercambios, los programas de intercambio cultural, estimulan las relaciones, el conocimiento de ambas economías y abren vías para que inversiones y comercio se incrementen. España debe potenciar la información y el conocimiento de los productos mexicanos y el acceso a los mismos para compensar el declinante protagonismo de la importación de petróleo.

Desde España, señala el Informe ELCANO 2016, las empresas han de sacar más partido al mercado de México como plataforma de acceso a los mercados de EE.UU. y Canadá. México es además una privilegiada vía de acceso al mercado centroamericano necesitados sus países de mayor cooperación cultural y económica.

\section{FUENTES ESTADÍSTICAS}

ICEX España exportación e Inversión. https://www.icex.es/icex/es. Última visita 23/03/2018

INE: http://www.ine.es/dyngs/INEbase

www.banxico.org.mx/Sielnternet/consultarDirectoriolnternetAction.do?sector=1\&accion=consultarDirectorioCuadros. Última consulta $21 / 03 / 2018$ 


\section{BIBLIOGRAFÍA}

-ALONSO, J.L. (2018): Relaciones económicas entre España y Brasil. Las exportaciones de España a Brasil en el siglo XXI. Rev. de Estudios Brasileños, Vol. 5, nº 9, pp. 11-28, marzo 2018 (DOI: https://doi.org/10.3232)

-ALONSO, J.L.; MENDES, A.A.; GUARNIERI, S.A. (2017): "Inversión exterior directa de España en Brasil 1996-2015", Rev. de Estudios Brasileños, Vol. 4, nº 6, pp. 176-190, abril 2017 (DOI: https://doi.org/10.3232)

BLANCO, H. (2000): "Relaciones hispano-mexicanas, el acuerdo con la UE", Economía Exterior, 12, pp. $33-39$ Botas, R. (2000):«La empresa española tras el acuerdo UE-México», Economía Exterior, 12, Madrid, pp. 112-121

CAMARA ESPAÑOLA DE COMERCIO (2017). MÉXICO-ESPAÑA. Análisis de exportaciones e importaciones, junio 2017, pp. 22. camescom.com.mx

CECEÑA, C. (2000): «Comercio bilateral entre España y México», Economía Exterior, 12, Madrid, pp. 77-87

CEPAL (2000): Ia Inversión Exterior Directa en América latina 1999. Capítulos II y III.

INFORMACIÓN COMERCIAL ESPAÑOLA (ICE): El sector exterior en 2016. Boletín Económico, n $3.088,1$ al 30 de junio de 2017, pp. 292.

ICEX. Informe del perfil de los exportadores a México 2017. Informe solicitado y emitido el 19 de marzo 2018, pp. 11.

ICEX. Plan Integral de Desarrollo de Mercado 2015. Ed. Digital, pp. 30

INFORME MÉXICO (2000). México. Entre dos vertientes económicas, Economía Exterior, 12, pp. 142-174

INSTITUTO DE COOPERACIÓN IBEROAMERICANA (1981): Las relaciones económicas entre España e lberoamérica. I Conferencia Iberoamericana de cooperación económica. Ediciones Cultura Hispánica, Madrid

LÓPEZ, M. (2001): "Relaciones Unión Europea-México", Economía Exterior, 19, pp. 109-116

MINISTERIO DE ECONOMÍA, INDUSTRIA Y COMPETITIVIDAD (2017): Estrategia de Internacionalización de la Economía Española 2017-2027, pp. 125

MORENO, M. Y PÉREZ, A. (2005): «Relaciones económicas y comerciales entre España y México», ICE, 821, pp. 225-237

OBSERVATORIO ESPAÑOL DEL MERCADO DEL VINO (2017): Memoria del mercado exterior del vino 2017 , pp. 62. www.oemv.es

OBSERVATORIO ESPAÑOL DEL MERCADO DEL VINO: Boletín 475 de 15/11/2017, pp.6

OFICINA ECONÓMICA Y COMERCIAL DE ESPAÑA EN MÉXICO (2004): Informe Económico y Comercial México, marzo, p. 27

REAL INSTITUTO ELCANO (2016): Relaciones España-México. Malamud, C. (Coord) Informe 21, pp. 129

REAL INSTITUTO ELCANO (2017):¿Por qué importa A. Latina?. Malamud, C. (Coord) Informe 22, pp. 93

RIVA, A. DE LA (2000): Asociación política y libre comercio", Economía Exterior, 12, pp. 63-67

RODRIGO, F. Y ARCE, L. (1999): México y la Unión Europea después del TLC. Economía Exterior, n 9, 121-128

ROMERO, J.L. (2001): «Relaciones comerciales España-México), Economía Exterior, 19, pp. 69-78

SÁNCHEZ, M. T. Y ALONSO, J.L. CASADO, J. Mª (2017): Inversión extranjera directa de España en México en la era del neoliberalismo económico. Dinámica temporal, estructura sectorial y distribución geográfica. Scripta Nova. Revista Electrónica de Geografía y Ciencias Sociales. Vol. XXI, n 556 , pp. 1-38

VELARDE, J. (1999): "Interrogantes españoles ante el futuro iberoamericano", Economía Exterior, 9, pp. 49-57 